\title{
Intergroup Competition Enhances Chimpanzee (Pan troglodytes verus) In-group Cohesion
}

\author{
L. Samuni ${ }^{1,2}$ (D) A. Mielke ${ }^{1,3,4} \cdot$ A. Preis ${ }^{1}$. \\ C. Crockford ${ }^{1,2} \cdot$ R. M. Wittig ${ }^{1,2}$
}

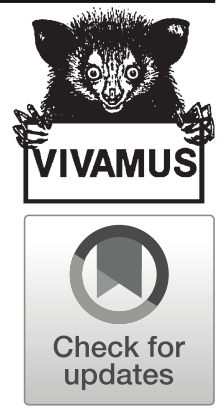

Received: 19 March 2019 / Accepted: 26 September 2019 / Published online: 18 December 2019

(C) The Author(s) 2019

\begin{abstract}
In-group cohesion is an essential component of successful intergroup competition in both human and nonhuman animals, likely facilitating group members access to potential benefits. However, when benefits are equally shared among group members, group defense becomes a collective action problem, which might subvert cohesive participation during intergroup competition. There is a lack of consensus across studies and species with regard to the link between in-group cohesion and intergroup competition, likely as a result of species differences in managing the collective action problem. Here, we examine this link in a species with a striking example of collective action during intergroup competition, chimpanzees (Pan troglodytes verus). Using two years of focal-follow data on males and females in two groups at the Taï Forest, Côte d'Ivoire, we investigated the immediate and long-term effects of intergroup competition (border patrols and intergroup encounters) on measures of in-group cohesion, namely modularity, party size, and intergroup aggression. We found that groups' association patterns were less modular (more cohesive) in months in which they engaged in more border patrols and intergroup encounters. We found that current and greater prior engagement in intergroup competition predicted larger party sizes. Furthermore, current, but not prior engagement in intergroup competition, predicted reduced intragroup aggression by males but not by females. Increased in-group cohesion in chimpanzees likely reduces potential costs of intergroup competition engagement, by facilitating joint participation in current and future intergroup conflicts, overcoming the collective action problem.
\end{abstract}

Keywords Collective action · Intergroup conflict · Pan troglodytes · Volunteer's dilemma

Handling Editor: Takeshi Furuichi

L. Samuni

liran_samuni@eva.mpg.de

Extended author information available on the last page of the article 


\section{Introduction}

Intergroup competition, or hostility between different social groups, is apparent across human societies (Bowles 2009) and regularly observed in many group-living primate and nonprimate species (Crofoot and Wrangham 2010; Kitchen and Beehner 2007; Radford 2008; Rusch and Gavrilets 2017; Wilson et al. 2014). Intergroup competition may incur high costs, increasing an individual's likelihood of injury or death, or generally affecting group members via potential loss of access to resources through the loss of group territory (Mitani et al. 2010). Suffering costs is heavily reliant on cohesive participation of group members during the competitive encounter, as power imbalance in favor of one group over the other predicts outcomes of competitive intergroup interactions (Radford 2008; Wrangham 1999). The benefits of successful intergroup encounters are likewise substantial, potentially influencing access to resources and thereby the fitness of a group and its members (Mitani et al. 2010; Radford and Fawcett 2014). Thus, if joint and cohesive group responses during intergroup competition influence the probability to access benefits, they are likely to be under strong selective pressure.

In territorial species with intergroup contest competition, collective group defense is crucial for maintaining a territory and for group members to access resources associated with territories. As such, territories can be seen as a public good that is roughly equally shared among group members (Olson 1965), meaning that there is minimal control for free-riders. Thus, collective group defense may present a collective action problem (Langergraber et al. 2017; Willems et al. 2013, 2015), especially with increasing group size and in species that live in a social system with high fission-fusion dynamics in which group members do not permanently associate. However, in many species, including humans, collective action and strength in numbers are key during intergroup conflicts (Majolo et al. 2019; Willems et al. 2015; Wrangham 1999), suggesting that species may overcome the collective action problem. Indeed, in humans, intergroup competition is known to engender solidarity, affiliation, and cohesion within a group (Bernhard et al. 2006; Gneezy and Fessler 2012; Puurtinen and Mappes 2009; Yamagishi and Mifune 2009). However, whether intergroup competition may enhance in-group cohesion and cooperation in other territorial social species remains unclear.

Several empirical studies in nonhuman animals have investigated how intergroup competition and in-group cohesion are linked, revealing conflicting results. Similar to humans, intergroup competition occurrence was associated with enhanced in-group affiliation and/or cohesion in several nonhuman primate and nonprimate species (Bruintjes et al. 2015; Majolo et al. 2016; Mirville et al. in press; Preis et al. 2019; Radford 2008; Samuni et al. 2017). However, other studies found no such relation (Cheney 1992; Chism and Rogers 2004; Grueter 2013; Polizzi di Sorrentino et al. 2012; Yi et al. 2019). This lack of consensus emphasizes that such a link likely depends on several factors such as the social system, the intensity of intergroup competition, and the potential cost-to-benefit ratios from group-level attacks on rivals. As in-group cohesion is suggested to be key in reducing costs and increasing potential benefits of competitive intergroup interactions, the link between intergroup conflict and in-group cohesion may simply be more pronounced in species where intergroup interactions are associated with extreme immediate costs, for instance when lethal.

Chimpanzees (Pan troglodytes) are well known for their highly structured territorial border patrols and intergroup encounters which are predominantly hostile (Furuichi in 
press; Wilson et al. 2014; Wrangham and Glowacki 2012), in contrast to the more tolerant nature of intergroup interactions in bonobos (Pan paniscus: Furuichi in press; Moscovice et al. in press). Chimpanzee intergroup encounters are highly risky, at times resulting in severe and lethal injuries (Wilson et al. 2014). Power asymmetries between rival groups directly influence the likelihood of suffering costs, as lethal violence occurs at times of power imbalance in favor of attackers (Wilson et al. 2014; Wrangham 1999; Wrangham and Glowacki 2012). Collective group defense in chimpanzees is essential for maintaining a territory, and if successful it may increase the group's access to valuable resources (Mitani et al. 2010; Wilson 2013). However, because of the high fission-fusion dynamics of chimpanzees and because collective group defense unselectively provides benefits to all group members, it may present a strong case of a collective action problem (Langergraber et al. 2017).

Despite the potential for individuals to free-ride, it has been suggested that species with philopatry and bonding of the larger sex, such as chimpanzees, may overcome the collective action problem (Willems et al. 2013). In addition, collective action may be maintained through intragroup aggression, for instance as a herding mechanism (Cooper et al. 2004) or punishment of free-riders (Radford et al. 2016). Such a mechanism is suggested in vervet monkeys (Chlorocebus pygerythrus), as increased female aggression toward in-group males during intergroup encounters enhanced future participation of these males in encounters (Arseneau-Robar et al. 2016). However, intragroup aggression in chimpanzees can disrupt social ties, thus reducing the predictability of coalitionary support and cooperation among group members (Aureli et al. 2002; de Waal 2000; Wittig and Boesch 2005), during intra- and intergroup interactions. Thus, intragroup aggression may instead pose a risk to collective action by increasing the likelihood of defection. This is especially true in chimpanzees, as competition between groups is extremely costly, such that a cohesive response and coalitionary support of group members are essential to reduce the costs of injury (Wilson et al. 2014; Wrangham 1999). Thus, examining the link between chimpanzee intergroup competition, a striking example of collective action, and in-group dynamics may reveal how chimpanzees are able to avert potential free-riding.

Here, we investigated this link in chimpanzees of two social groups in the Taï Forest, Côte d'Ivoire. Although male chimpanzees initiate and lead competitive intergroup interactions, both males and females participate in the majority of intergroup interactions in this population (Samuni et al. 2017). Furthermore, males and females from the two social groups were more likely to stay together (fission less) during territorial activity (Samuni et al. 2017), indicating higher group cohesiveness when the risk is at its highest. However, it is unclear whether like in humans, intergroup competition influences in-group cohesion after the end of the intense conflict. For instance, as intergroup competition occurrence fluctuates through time, one could expect a dynamic effect of such conflicts on measures of in-group cohesion, defined as the tendency for a group to be in unity while pursuing a goal (Carron and Brawley 2000). Furthermore, it remains to be tested whether chimpanzees use intragroup aggression as a mechanism to maintain collective action.

For that purpose, we investigated the relationship between chimpanzee territorial activity (i.e., border patrol and intergroup encounter) and various measures of in-group cohesion. Chimpanzees show high fission-fusion dynamics, in which individuals from the same group split into smaller and dynamic parties of varying size, duration, and 
composition (Boesch and Boesch-Achermann 2000). Thus, we capitalized on the highly dynamic association patterns of chimpanzees to evaluate two different measures of group cohesion, that is, monthly group clustering patterns (modularity) and daily party size. Furthermore, we evaluated rates of intragroup aggression as an additional measure of in-group cohesion. In addition, to disentangle a potential causal relationship between territorial activity occurrence and in-group cohesion we applied and tested two different measures of intergroup competition 1) daily occurrence of territorial activity (immediate) or 2) accumulative previous occurrence of territorial activity (long term).

As large groups may increase the risk of a collective action problem arising (Olson 1965), we predicted that increased territorial activity will be associated with higher group modularity and smaller association parties both during and after territorial activity. However, group defense in chimpanzees is considered as an example of overcoming the collective action problem, and strength in numbers during intergroup competition is highly beneficial (Langergraber et al. 2017; Wilson et al. 2014; Wrangham 1999). In accordance with this rationale, we alternatively hypothesized that territorial activity will enhance intragroup cohesion. Thus, we predicted that chimpanzee groups will be less modular (the group as a whole will be more cohesive), and associate in larger parties both during and as a consequence of intergroup conflicts. Furthermore, if intragroup aggression functions to herd or punish free-riders, we predicted that territorial activity will be associated with and promote increased intragroup aggression. Conversely, when competition with neighboring groups is high, coalitionary support and cooperation are essential to reduce costs of injury from rivals. Thus, because intragroup aggression is likely to reduce predictability of coalitionary support and cooperation, we predicted lower intragroup aggression both on days of and after territorial activity. As males are the main instigators of territorial activity and are more aggressive than females in general, and because females compete for resources mainly in order to support their young, we predicted that the effect of territorial activity on intragroup aggression is sex specific, with a stronger influence of intragroup aggression in males than in females.

\section{Methods}

We conducted fieldwork with the Taï Chimpanze Project at the Taï National Park, Côte d'Ivoire $\left(5^{\circ} 45^{\prime} \mathrm{N}, 7^{\circ} 7^{\prime} \mathrm{W}\right)$ on two well-habituated chimpanzee (Pan troglodytes verus) groups (i.e., East and South group), over two periods in 2013-2015, each extending from September to May. During the study, the adult group size varied from 15 to 18 adult individuals in East (5 males and 10-13 females) and 17-21 adult individuals in South (5 males and 12-16 females), as the result of several deaths and immigration events.

\section{Behavioral Data Collection}

We collected data using all-day focal animal sampling (Altmann 1974) of all adult males and females $>12 \mathrm{yr}(N=38$ individuals), with the exception of one recent immigrant female that was not fully habituated at the time. Focal follows included documentation of all submissive and aggressive interactions and changes in association patterns (noting each change in party composition). For the aggression data, we 
documented the direction and partner's identity for all types of directed aggressive interactions (i.e., display, threat, charge, chase, attack). For party association data, we recorded the presence of all adults within visual range (usually $30-50 \mathrm{~m}$ ) of the focal subject (Mielke et al. 2017). The number of observers in each group varied between one and four observers per day, and when several observers simultaneously observed the same party, we included it as a single data point in the data set. We recorded 5256 observation hours in East group and 5564 in South group during 1272 daily focal follows, which, owing to multiple observers, occurred on 392 and 399 unique dates in South and East, respectively. We followed females in $40 \%$ of all focal follows.

As dominance rank may influence aggressive behavior, we used unidirectional submissive pant grunt vocalizations collected during focal follows to determine the in-group dominance relationships. We applied a likelihood-based adaptation of the Elo rating approach (Foerster et al. 2016; Mielke et al. 2017; Neumann et al. 2011) to estimate the dominance hierarchy for each of the sexes separately (Samuni et al. 2018a), standardized to a range from 0 to 1 .

\section{Border Patrols and Intergroup Encounters}

During focal follows we documented all-occurrence of border patrols and intergroup encounters (i.e., territorial activity) observed. Chimpanzee border patrols are characterized by cautious and quiet movements of several group members toward, around, and beyond their territory border areas (Boesch et al. 2008; Furuichi in press; Langergraber et al. 2017; Samuni et al. 2017; Watts and Mitani 2001). Chimpanzees on border patrols typically decrease their foraging behavior and investigate primary (e.g., vocalizations) and secondary (e.g., feeding remains, feces, nests) cues of neighboring chimpanzee groups (Samuni et al. 2017; Watts and Mitani 2001). If individuals hear or encounter neighboring chimpanzees, they often engage in hostile interactions, such as aggressive vocalizations, displays, and attacks against the out-group. Not all intergroup encounters result in direct contact with neighbors, and some encounters are limited to vocal exchanges over extended distances. The imposed risk of territorial activity varies both within and between border patrols and intergroup encounters. However, owing to the ambush-like nature of attacks and the challenge of assessing group size advantage over a distance, a high uncertainty of risk is apparent with participation in all types of territorial activities. Nonetheless, regardless of outcome, cohesive participation likely reduces this uncertainty. Therefore, we do not differentiate between border patrols and intergroup encounters. If a border patrol and an intergroup encounter occurred on the same day with the same neighboring group, we analyzed it as a single occurrence of territorial activity for that respective day. On no single day were there encounters with multiple neighboring groups.

\section{GPS Location Data}

During focal follows we collected data on the location of the focal subject using a GPS (Garmin@ 62 or Rino 610) set on the automatic tracklog recording function. We used the tracklog data and kernel density estimate (Worton 1989) to assess the proximity of the focal individual to the border areas of the territory and to construct the home ranges of the two groups. We did this to consider potential influences of border proximity on 
aggression and association patterns. The proximity to the border constituted the percentage of home range usage kernels, ranging from 5 to 99, with 99 representing the extreme of the border area (Samuni et al. 2017). The home ranges (95\% kernel) of the two groups between September 2013 and May 2015 were comparable: East, 32 $\mathrm{km}^{2}$; South, $35 \mathrm{~km}^{2}$. As the availability of food resources is a potential driver of territorial activity, we collected long-term phenology data on the availability of fruiting trees within the home range of each social group (see the next section).

\section{Fruit Availability Index}

We used phenology data collected at the Taï Chimpanzee Project between September 2013 and May 2015 to calculate fruit availability index $\left(\mathrm{FA}_{m}\right)$. We collected information on the presence of mature fruits, tree density, and tree basal area of the 74 most frequently eaten species for the chimpanzees, separately for East and South groups (925 and 623 individual trees in East and South, respectively). The FA $m$ index for each group was calculated monthly, following a standard index for Taï chimpanzees (Anderson et al. 2002, 2005).

For month $m$, the fruit availability index $\mathrm{FA}_{m}$ was defined as follows:

$$
\mathrm{FA}_{m}=\sum_{k=1}^{n} D_{k} B_{k} P_{k m}
$$

where

$D_{k} \quad$ density of species $k$ across the study area

$B_{k} \quad$ mean basal area (measured by trunk diameter at breast height) of species $k$ across the study area

$P_{k m} \quad$ percentage of observed fruiting tree species $k$ with mature fruits across the study area in month $m$.

\section{Statistical Analysis}

Modularity Model We used party association data to construct matrices of monthly dyadic association values of all adult subjects, accounting for the time two subjects in a dyad were observed in the same party as a function of the observation time of both subjects. We used the dyadic association matrices to determine monthly group modularity. Modularity is a social-networks measure that represents the degree to which ingroup individuals are divided into particular clusters (Farine and Whitehead 2015). Thus, this measure identifies the degree to which individuals in a particular social group (i.e., chimpanzee community) associate with other group members across a continuum. Whereas values close to 1 represent clear small clusters of individuals that have strong connections with each other and few connections between clusters, values close to 0 represent groups in which all individuals associate together or have strictly random association patterns. We determined the monthly modularity values with the "greedy algorithm" approach (Clauset et al. 2004; Newman 2006) using the fastgreedy.community function of the R package igraph (Csardi and Nepusz 2006).

We ran a multivariate linear regression (modularity model) to investigate the effect of participation in territorial activity (i.e., border patrol and intergroup encounters) on 
group monthly modularity (square root transformed). We included border patrols and intergroup encounters as types of territorial activity, as both are associated with risk and involve a high degree of uncertainty with regard to potential interactions with rivals. To reliably estimate the effect of territorial activity on group modularity, we controlled for factors that may influence group association patterns. Thus, we included monthly fruit availability (as described earlier), the number of sexually receptive females (Anderson et al. 2002), and group identity (i.e., East or South). We operationalized the number of sexually receptive females as the number of females that showed maximum tumescence of the perineal skin on visual inspection on at least one day of the month. In addition, as hunting is another group collective activity that involves the acquisition of a resource in chimpanzees (Samuni et al. 2018b), it may influence modularity. Thus, we controlled for the number of days in which hunting occurred during the month.

We only included months with $>20$ nest-to-nest observation dates (mean $\pm \mathrm{SD}$ : $27.03 \pm 3.19$ days per month), resulting in a total 29 months (15 months in East and 14 in South; 3 months were excluded). We accounted for variation in observation days across months by including weighted least squares regression of the number of observation days per month, using "weights."

Group Defense Score The modularity model investigates the general association between engagement in territorial activity and in-group cohesion, and hence does not test the causal relationships between the two. To test whether territorial activity directly influences parameters of in-group cohesion we used the frequency of previous territorial activities to calculate a continuous measure of group defense participation, as territorial activity may influence in-group dynamics days after its occurrence. We evaluated the group defense score separately for each observation field period (October 2013-May 2014 or September 2014-May 2015) by summing all previous territorial activities until the day previous to the focal observation day weighted by the inverse of the number of prior days (Fig. 1). Thus, if a territorial activity occurred $N$ days before the focal observation day, it adds $1 / N$ to the group defense score. Territorial activities that occurred during the focal observation day were not included in the group defense score calculations for that day. We used long-term data on the occurrence of territorial activities during the first month of each observation field period (September 2013 or August 2014) as a burn-in period. Using this approach, previous days in which territorial activity was recorded had a relative positive impact on the group defense score, which decreased with time passed (mean $\pm \mathrm{SD}$ : $0.59 \pm 0.6$ ranging 0-3.12). As an example, if a territorial activity occurred one day before the focal day, it added a 1.0 to the group defense score, and if it occurred 10 days before the focal day, it added 0.1 to the group defense score. The group defense score increased only in case an intergroup encounter or border patrol occurred and was not positively influenced by the time passed since the start of the observation field period (correlation between Julian date and group defense score: East, first field period: -0.08 , second field period: 0.05; South, first field period: 0.49 , second field period: 0.1 ).

Party Size Model While the modularity measure identifies whether association patterns within the group are consistent and clustered, it does not provide a good indication of the size of association parties, which might be highly relevant during territorial activity considering that large group size may facilitate access to benefits. Thus, to further 


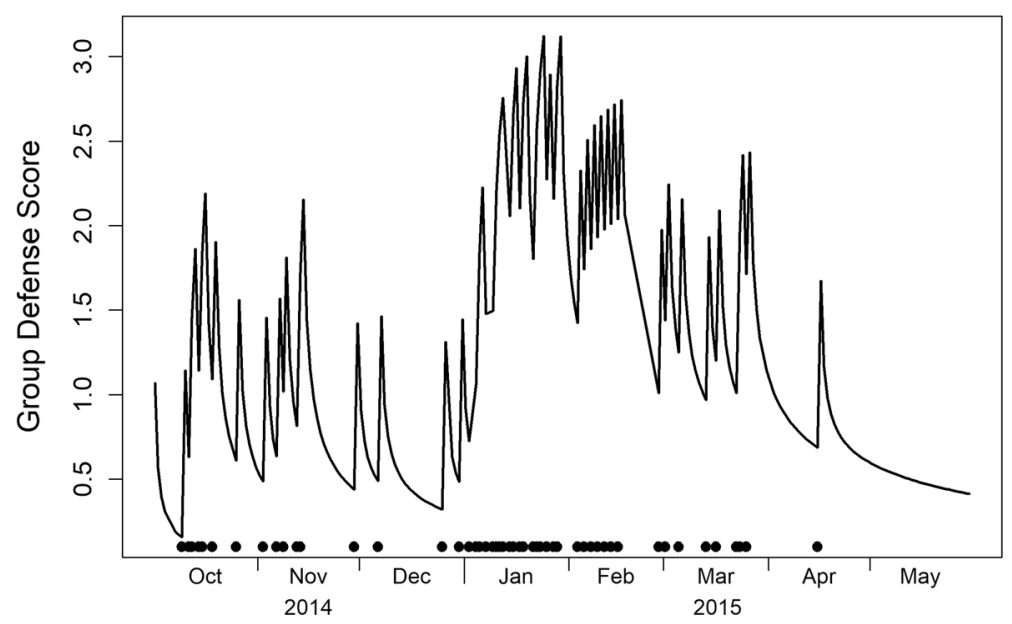

Fig. 1 Depiction of the group defense score for the East chimpanzee group, in Taï Forest, Côte d'Ivoire, between September 2014 and May 2015. The line tracks the score across time and the black points denote the occurrence of territorial activity. For every given day the group defense score reflects the occurrence of previous territorial activities, such that each previous territorial activity adds a value to the group defense score equal to the inverted number of days past since its occurrence.

evaluate the effect of territorial activity on in-group dynamics, we fitted a linear mixed model (LMM; Baayen, 2008) with Gaussian error structure and identity link function, with mean daily party size as the response (party size model). We calculated mean party size daily (1272 focal days; 791 unique dates) per focal subject $>12$ yr (38 individuals) measured as $\sum$ (party size $\times$ party duration $) / \sum$ (party durations). In this model we tested for both 1) immediate (whether the subject participated in territorial activity during the focal observation day) and 2) long-term ("group defense score") effects of territorial activity on the response. To account and control for the effect of key ecological and social variables we controlled for the sex of the focal individual, group membership (i.e., East and South), the presence of fully tumescent females during the focal day, and general fruit availability. Furthermore, we controlled for the occurrence of hunting behavior during the focal day, and the proximity to the border at the morning nest site. As we expect circannual variation in mean party size (McCarthy et al. 2018), we converted Julian dates into a circular variable and included its sine and cosine in the model (Stolwijk et al. 1999). The seasonal term reflects variation in ecological factors that likely influence party size (Wessling et al. 2018). We included event (combination of group and date, $N=791$ ) and subject identities as random effects to account for nonindependent sampling of certain subjects or events disproportionally affecting the mean party (avoiding pseudoreplication). Furthermore, to keep type I error rate at the nominal 5\%, we included random slopes (Barr et al. 2013; Schielzeth and Forstmeier 2009) for group defense score, occurrence of territorial activity and hunting, presence of fully tumescent females, and fruit availability within subjects.

Consecutive focal follow days may occur under more similar social or ecological conditions unexplained by the fixed effects included in the model but are likely to affect the response variable (mean party size). For instance, this may be the clumpiness of food resources, which the fruit availability measure does not account for. This may lead to violation of the assumption of independent residuals (by temporally close residuals 
potentially being more similar than distant ones). Therefore, we incorporated temporal autocorrelation into the party size model by first fitting the model (as described earlier) to derive the model residuals. We then calculated a temporal "autocorrelation term" for each data point by averaging the residuals of all other data points of the same group, with the contribution of the residuals being weighted by their time lag to the particular data point. The weighting function followed a normal distribution, with its standard deviation determined by maximizing the likelihood of the model with the temporal autocorrelation term included. We then included the "autocorrelation term" as an additional fixed effect into the model.

Intragroup Aggression Model Finally, we fitted a generalized linear mixed model (GLMM) with Poisson error structure and log link function, to test the effect of territorial activity on measures of adult-adult intragroup aggression (intragroup aggression model), using the same data set as per the party size model. As intragroup aggression may facilitate collective action by herding or punishing specific free-riders, we calculated intragroup aggression as the number of directed aggressions focal individuals gave others during focal follow days and tested whether this was influenced by territorial activity participation. As we aimed to evaluate the intragroup aggressive tendencies of focal individuals, we included only daily intragroup aggressions given (we did not include intragroup aggressions received or intergroup aggression given or received). We incorporated the same test predictors in this model as in the party size model and added interactions between the two test predictors and sex (group defense score $\times$ sex and participation in territorial activity $\times$ sex), as male chimpanzees are more aggressive than females in general. Here, we controlled for the same variables as the party size model but added two additional control variables of dominance rank and mean daily party size. Furthermore, we added the number of observation hours as an offset term to account for increased likelihood of observing aggression with increased observation time. As per the party size model we included event $(N=791)$ and subject identities with random slopes for group defense score, occurrence of territorial activity and hunting, presence of fully tumescent females, fruit availability, dominance rank and party size within subject, and dominance rank and party size within event. We did not include an autocorrelation term.

Model Design and Validation We fitted all models in R (version 3.4.4; R Core Team, 2016) using the functions lm, lmer, or glmer of the R package lme4 (Bates et al. 2015). Using a likelihood ratio test we compared the fit of all full models with those of a respective null model lacking only the test predictors, but otherwise identical to the respective full model in all other terms (Forstmeier and Schielzeth 2011). If an interaction term had no significant effect, we ran a reduced model including only the main effects. In each model, we tested the significance of the fixed effects using the dropl function in $\mathrm{R}$, by systematically dropping them from the model one at a time (Barr et al. 2013) and comparing the respective reduced model lacking the individual fixed effects with the full model.

Before fitting the models, we checked all predictors and the response for their distribution. Overdispersion was not detected in the Poisson model (dispersion parameter $=0.61$ ). We then proceeded by $z$-transforming the covariates of group defense score, fruit availability, party size, dominance rank, and the monthly values of hunting and fully tumescent females 
(Schielzeth 2010). We verified the assumptions of normally distributed and homogeneous residuals by visual inspection of qq-plots and residuals plotted against fitted values. This did not reveal obvious deviations from model assumptions. Model stability was assessed for the LMM (party size model) and GLMM (intragroup aggression model) by excluding the random effects one at a time and comparing the estimates derived for these data with those derived for the full data set. This revealed no influential subjects or events to exist. For these two models we as well derived confidence intervals by means of parametric bootstraps (function bootMer of the package lme4). For the modularity model we assessed model stability by inspecting dfbeta values (Field 2013). We used the function vif of the R package car (Fox and Weisberg 2011) applied to a standard linear model lacking the random effects to derive variance inflation factors (VIF), which did not reveal collinearity problems (largest VIF: modularity model $=2.56$; party size model $=2.97$; intragroup aggression model $=1.3$ [Quinn and Keough 2002]). Modularity and mean party size are likely influenced by group size, owing to the number of potential association partners. However, as we are not interested in group differences in the responses, and as group membership is highly correlated with group size (VIF > 9), we do not account for the group size here but rather control for group membership (East and South) in both analyses.

\section{Ethical Note}

All methods used in this study were noninvasive and were approved by the Ministry of Higher Education and Scientific Research of Côte d'Ivoire and the Office Ivoirien des Parcs et Réserves. All aspects of the study comply with the ethics policy of both the Max Planck Society and the Department of Primatology of the Max Planck Institute for Evolutionary Anthropology, Germany, and the American Society of Primatologists principles for the ethical treatment of nonhuman primates. The authors declare no conflict of interests.

Data Availability The data set used in fitting the models is available upon request.

\section{Results}

During the study period we observed 34 border patrols and 39 intergroup encounters in East group, and 6 border patrols and 27 intergroup encounters in South group. Although 9 encounters (6 in East and 3 in South) involved an attack on a few isolated outgroup individuals, we did not observe any cases of killing or severe injuries during the study period. Furthermore, we did not observe any cases of immediate retreat of group members to core areas after detecting neighboring groups. In all border patrols or intergroup encounters at least one male was present in both East and South groups. Females participated in 91 of the 106 documented territorial activities, with a range of 0-11 females per event. The number of participants per territorial activity event was $($ mean \pm SD) $4.59 \pm 0.82$ for males and $4.62 \pm 3.57$ for females.

Monthly frequency of territorial activity varied 0-19 days on a given month. The overall modularity values were generally low and ranged from 0.012 to 0.199 . We 
found that territorial activity was significantly associated with group modularity $(F=$ 5.30, $\mathrm{df}=23, P=0.030$; Table I), such that the social groups were less clustered (i.e., more cohesive) on months in which they participated in more territorial activities (estimate \pm SE: $-0.277 \pm 0.120$; Fig. 2). Furthermore, we found that East group was less modular than South group $(1.294 \pm 0.361, P=0.002)$. The number of monthly hunting cases, fully tumescent females, or fruit availability had no significant effect on group modularity (Table I). To ensure that these results were not influenced by months with extreme numbers of territorial activities, we reran the multivariate regression excluding one outlier month (19 different territorial activities during 28 observation days in East). This procedure revealed that the effect of territorial activity occurrence on modularity was not driven by this outlier $(P=0.005)$.

The mean party size full-null model comparison was significant (likelihood ratio test: $\chi^{2}=99.897$, df $=3, P<0.001$; Table II). Specifically, we found that mean party size increased with both increasing recent group defense scores (estimate \pm SE: $0.332 \pm$ $0.090 ; P=0.001 ;$ Fig. 3 ), and the occurrence of territorial activity (estimate \pm SE: 1.101 $\pm 0.227 ; P<0.001$; Fig. 4). Moreover, we found larger mean party sizes on days when fully tumescent females were present (estimate $\pm \mathrm{SE}: 0.828 \pm 0.159 ; P<0.001$ ), and in South group individuals (estimate $\pm \mathrm{SE}: 0.815 \pm 0.238 ; P=0.001$ ). We as well found a seasonal variation in mean party size (likelihood ratio test comparing the full model with one lacking the two terms accounting for season: $\chi^{2}=19.680, \mathrm{df}=2, P<0.001$ ). The sex of the focal subject, occurrence of hunting behavior, proximity to the border, and fruit availability had no significant effect on mean party size.

Rates of in-group directed aggressions differed between males with $1.14 \pm 1.77$ aggressions given per observation day (range, $0-22$ ), and females $0.75 \pm 1.39$ aggressions given per observation day (range, 0-13). Testing the rates of adult-adult intragroup directed aggressions, the full-null model comparison was significant (likelihood ratio test: $\chi^{2}=13.235$, $\mathrm{df}=5, P=0.021$; Table III). The interaction between group defense score and sex was not significant $(P=0.900)$. We found a significant effect of the interaction between sex and the occurrence of territorial activity during the focal day $(P=0.038$; Fig. 5). Specifically, post hoc procedures revealed that males were

Table I Effect of territorial activity on group modularity (square root transformed)

\begin{tabular}{|c|c|c|c|c|c|}
\hline Term & Coded level & Estimate $\pm \mathrm{SE}$ & $95 \% \mathrm{CI}$ & $F$ & $P$ \\
\hline \multicolumn{6}{|l|}{ Test predictor levels } \\
\hline Intercept & & $-3.397 \pm 0.203$ & $-3.819,-2.978$ & - & - \\
\hline Territorial activity ${ }^{\mathrm{a}}$ & & $-0.277 \pm 0.120$ & $-0.530,-0.025$ & 5.307 & 0.030 \\
\hline \multicolumn{6}{|l|}{ Control predictors } \\
\hline Hunting activity ${ }^{\mathrm{b}}$ & & $0.180 \pm 0.140$ & $-0.104,0.480$ & 1.646 & 0.212 \\
\hline Group (East) & South & $1.294 \pm 0.361$ & $0.548,2.044$ & 12.887 & 0.002 \\
\hline Fruit availabilityc & & $0.148 \pm 0.123$ & $-0.102,0.407$ & 1.450 & 0.241 \\
\hline \multicolumn{2}{|c|}{ Number of fully tumescent females ${ }^{\mathrm{d}}$} & $-0.250 \pm 0.162$ & $-0.588,0.086$ & 2.363 & 0.138 \\
\hline
\end{tabular}

Territorial and hunting activity represents the number of days with intergroup encounters and border patrols, or hunting, respectively, on a given month in chimpanzees in Taï Forest, Côte d'Ivoire, 2013-2015. Statistically significant results $(P<0.05)$ appear in bold

${ }^{\mathrm{a}-\mathrm{d}} z$-transformed, mean $\pm \mathrm{SD}$ of the original variables: ${ }^{\mathrm{a}} 3.2 \pm 3.95,{ }^{\mathrm{b}} 6 \pm 4.3,{ }^{\mathrm{c}} 1.82 \pm 1.2,{ }^{\mathrm{d}} 5.3 \pm 2.94$. 


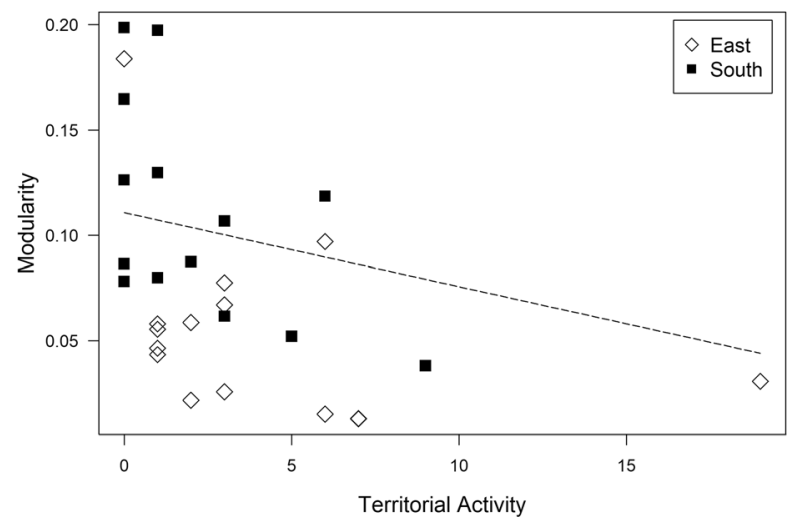

Fig. 2 The effect of monthly rates $(29 \mathrm{mo}$ ) of territorial activity (days per month) on group modularity measure in chimpanzees in Taï Forest, Côte d'Ivoire, 2013-2015. Low modularity scores represent less clustered (more cohesive) group association patterns. Points denote monthly modularity values of East (empty diamonds) and South (filled squares) groups. The dashed line is the regression line obtained from the full modularity model.

less likely to aggress others on days in which they participated in territorial activity (no territorial activity vs. territorial activity: $0.440 \pm 0.210 ; P=0.036$ ), whereas there was no significant difference for females in aggressions given between days in which they participated in territorial activity or not (territorial activity vs. no territorial activity:

Table II LMM (party size model) testing the effect of daily territorial activity occurrence (immediate) and group defense score (long term) and on mean party size weighted by party duration

\begin{tabular}{|c|c|c|c|c|c|}
\hline Term & Coded level & Estimate $\pm \mathrm{SE}$ & $95 \% \mathrm{CI}$ & $\chi^{2}$ & $\underline{\mathrm{P}}$ \\
\hline \multicolumn{6}{|l|}{ Test predictor levels } \\
\hline Intercept & & $5.830 \pm 0.223$ & $5.406,6.288$ & - & - \\
\hline Group defense score ${ }^{a}$ & & $\mathbf{0 . 3 3 2} \pm \mathbf{0 . 0 9 0}$ & $0.157,0.500$ & 12.040 & 0.001 \\
\hline Territorial activity & Yes & $1.101 \pm 0.227$ & $0.659,1.536$ & 18.457 & $<0.001$ \\
\hline \multicolumn{6}{|l|}{ Control predictors } \\
\hline Hunting & Yes & $0.146 \pm 0.194$ & $-0.208,0.552$ & 0.561 & 0.454 \\
\hline Fully tumescent female & Yes & $0.828 \pm 0.159$ & $0.494,1.156$ & 21.020 & $<0.001$ \\
\hline Sex & Male & $0.134 \pm 0.216$ & $-0.299,0.578$ & 0.373 & 0.541 \\
\hline Group & South & $0.815 \pm 0.238$ & $0.323,1.265$ & 10.545 & 0.001 \\
\hline \multicolumn{2}{|l|}{ Fruit availability ${ }^{\mathrm{b}}$} & $0.145 \pm 0.120$ & $-0.098,0.378$ & 1.451 & 0.228 \\
\hline \multicolumn{2}{|l|}{ Proximity to border ${ }^{c}$} & $0.058 \pm 0.077$ & $-0.093,0.215$ & 0.565 & 0.452 \\
\hline \multicolumn{2}{|c|}{ Temporal autocorrelation term } & $2.478 \pm 0.231$ & $2.004,2.969$ & 92.894 & $<0.001$ \\
\hline \multicolumn{2}{|c|}{ Sine (Julian date) } & $-0.630 \pm 0.131$ & $-0.880,-0.366$ & \multirow{2}{*}{19.680} & \multirow{2}{*}{$<0.001$} \\
\hline \multicolumn{2}{|l|}{ Cosine (Julian date) } & $-0.566 \pm 0.231$ & $-1.008,-0.137$ & & \\
\hline
\end{tabular}

$N=1272$ observation days of 38 chimpanzees in Taï Forest, Côte d'Ivoire, 2013-2015.Statistically significant results $(P<0.05)$ appear in bold.

${ }^{\mathrm{a}-\mathrm{c}} z$-transformed, mean $\pm \mathrm{SD}$ of the original variables: ${ }^{\mathrm{a}} 0.59 \pm 0.60,{ }^{\mathrm{b}} 1.83 \pm 1.13,{ }^{\mathrm{c}} 67.67 \pm 31.42$ (range, $5-$ 99). 


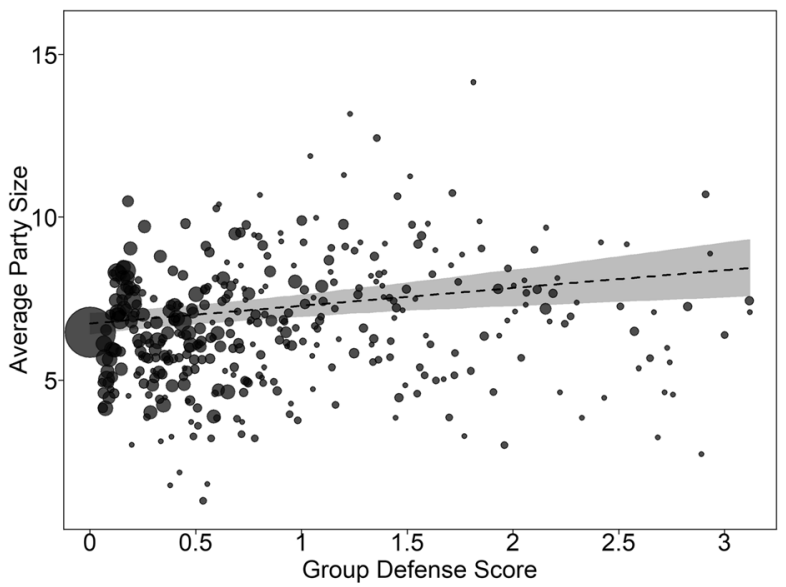

Fig. 3 The effect of the group defense score on group mean party size in chimpanzees in Taï Forest, Côte d'Ivoire, 2013-2015 ( $N=1272$ data points; 38 subjects). Shown are the observed mean party size (larger point areas denote a larger number of observations) as well as the model result (dashed line) and confidence intervals (gray area) as obtained from the party size model.

$0.244 \pm 0.275 ; P=0.376$ ). In contrast, we did not find a significant effect of long-term group defense score on the number of aggressions given in either males or females $(-0.061 \pm 0.054 ; P=0.239)$. Party size and hunting behavior had a significant effect on aggressions given, such that we found fewer aggressions on days of hunting behavior $(-0.343 \pm 0.120 ; P=0.003)$ and more aggressions with an increase in party size $(0.266$ $\pm 0.062 ; P<0.001)$. The dominance rank of the subject, presence of fully tumescent females, general fruit availability, and group membership had no significant effect on aggressive acts.

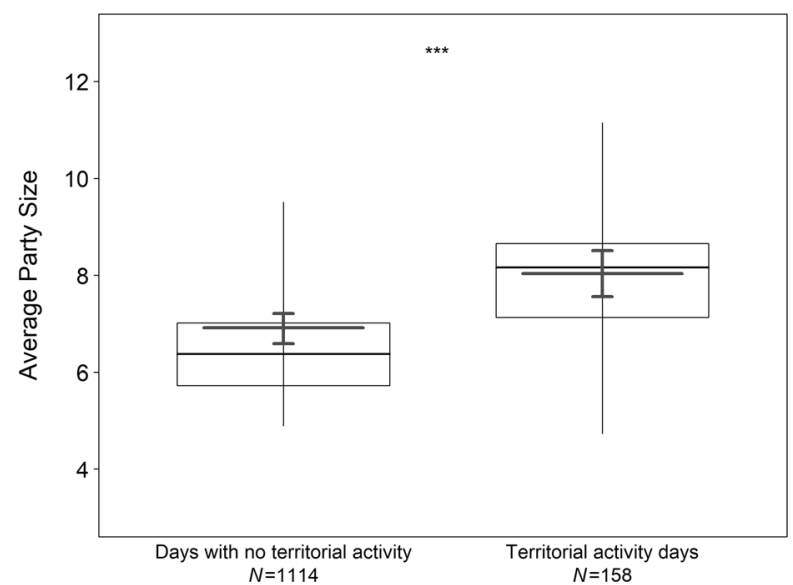

Fig. 4 Effects of territorial activity participation on mean party size in chimpanzees in Taï Forest, Côte d'Ivoire, 2013-2015 ( $N=1272$ data points; 38 subjects; 2 groups). Shown are medians (thin horizontal lines), quartiles (boxes), percentiles (2.5\% and 97.5\%; vertical lines) as well as the fitted model and its $95 \%$ confidence intervals (thick gray lines and error bars). 
Table III LMM (intragroup aggression model) testing the effect of daily territorial activity occurrence (immediate) and group defense score (long term) and on intragroup aggressions given

\begin{tabular}{|c|c|c|c|c|c|}
\hline Term & Coded level & Estimate $\pm \mathrm{SE}$ & $95 \% \mathrm{CI}$ & $\chi^{2}$ & $P$ \\
\hline \multicolumn{6}{|l|}{ Test predictor levels } \\
\hline Intercept & & $-2.978 \pm 0.153$ & $-3.295,-2.687$ & - & - \\
\hline Group defense score ${ }^{a}$ & & $-0.061 \pm 0.054$ & $-0.178,0.036$ & 1.387 & 0.239 \\
\hline Territorial activity & Yes & $0.244 \pm 0.275$ & $-0.344,0.734$ & - & - \\
\hline Sex & Male & $0.461 \pm 0.117$ & $0.208,0.702$ & - & - \\
\hline Territorial activity $\times$ Sex & Yes $\times$ male & $-0.660 \pm 0.332$ & $-1.280,0.012$ & 4.304 & 0.038 \\
\hline \multicolumn{6}{|l|}{ Control predictors } \\
\hline Hunting & Yes & $-0.343 \pm 0.120$ & $-0.589,-0.122$ & 8.567 & 0.003 \\
\hline Fully tumescent female & Yes & $0.251 \pm 0.150$ & $-0.038,0.563$ & 2.935 & 0.087 \\
\hline Mean party size ${ }^{b}$ & & $0.266 \pm 0.062$ & $0.145,0.392$ & 13.796 & $<0.001$ \\
\hline Dominance rank ${ }^{c}$ & & $-0.001 \pm 0.085$ & $-0.003,0.001$ & -0.005 & 1.000 \\
\hline Group & South & $-0.036 \pm 0.120$ & $-0.271,0.202$ & 0.201 & 0.654 \\
\hline Fruit availability ${ }^{d}$ & & $0.054 \pm 0.060$ & $-0.073,0.170$ & 0.732 & 0.392 \\
\hline
\end{tabular}

$N=1272$ observation days of 38 chimpanzees in Taï Forest, Côte d'Ivoire, 2013-2015.Statistically significant results $(P<0.05)$ appear in bold.

${ }^{\mathrm{a}-\mathrm{d}} z$-transformed, mean $\pm \mathrm{SD}$ of the original variables: ${ }^{\mathrm{a}} 0.59 \pm 0.60,{ }^{\mathrm{b}} 6.65 \pm 2.66,{ }^{\mathrm{c}} 0.66 \pm 0.24$ (range $0-1$ with 1 being the highest social rank in each sex category), ${ }^{\mathrm{d}} 1.83 \pm 1.13$.

\section{Discussion}

Our results provide evidence that link territorial activity and dynamics of in-group cohesion in a species with predominantly hostile intergroup interactions. We found that territorial activity influences group modularity, association patterns, and intragroup aggression in two distinct social groups of chimpanzees. Specifically, on a group level, we showed a correlation between higher monthly participation in territorial activity and less clustered monthly subgroup division. Furthermore, we found that territorial activity positively

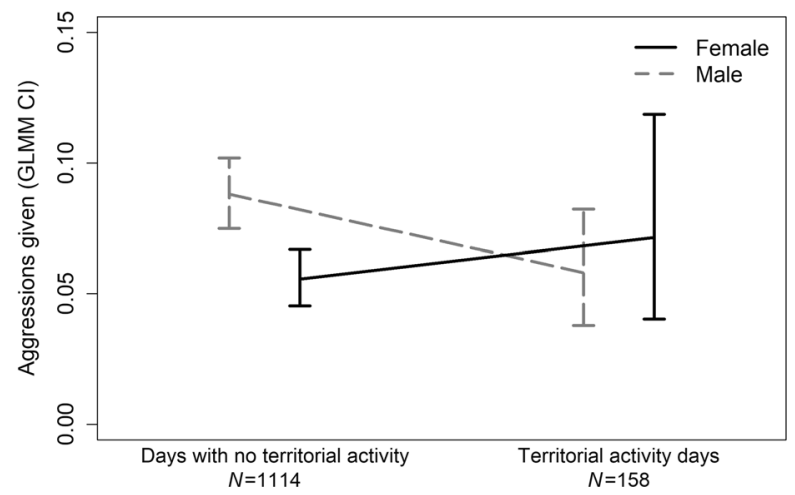

Fig. 5 Effects of territorial activity participation on adult-adult aggressions given $(N=1272$ data points; 38 subjects; 2 groups) in males (dashed gray) and females (full black) in chimpanzees in Taï Forest, Côte d'Ivoire, 2013-2015. Shown are the 95\% confidence intervals (CI) of the GLMM intragroup aggression model (the dashed and full horizontal lines connect between the fitted model values for each sex). 
influenced average party size of males and females, both on the immediate scale (territorial activity occurrence) and post territorial activity (group defense score). Lastly, territorial activity occurrence had a negative effect on intragroup aggressions given in males, but not females, demonstrating an attenuating effect of intergroup competition on intragroup competition. Importantly, we demonstrated these effects while controlling other variables known to influence association patterns or intragroup aggression, such as food availability, presence of fully tumescent females, dominance rank, or temporal autocorrelation.

Collective action during territorial activity should evolve when it is crucial for maintaining a territory and when the direct or indirect benefits gained by group members outweigh the costs (Olson 1965). However, when collective action creates a public good (e.g., territory) that is equally shared independent of participation, natural selection will favor free-riders over cooperators, leading to a collective action problem (Olson 1965). This problem is likely more pronounced in larger groups when the relative impact of each individual on the outcome in case of defection is small. However, opposing such predictions, we found that current and greater previous engagement in territorial activity predicted larger party sizes. Furthermore, although intragroup aggression is suggested as a mechanism to overcome the collective action problem by punishing free-riders (Radford et al. 2016), we did not find support for this here. The fact that chimpanzees collectively act to defend their territory and that territorial defense is tightly linked with group homogeneity and cohesion (Langergraber et al. 2017; Samuni et al. 2017; Wrangham 1999) emphasizes that the collective action problem does not subvert group level cooperation during competitive interactions with out-groups in chimpanzees. This is not surprising, given that access to benefits of territorial activity in chimpanzees is closely linked to cohesive participation (Mitani et al. 2010; Wilson et al. 2014; Wrangham 1999), and thus may make freeriding a suboptimal strategy in that species. For instance, chimpanzees' collective action during territorial defense can be seen as an example of the volunteer's dilemma (Archetti 2009; Diekmann 1985), in which the public good is produced only when a minimum number of individuals participate. Specifically, when the production of the public good is highly beneficial and more likely with increased participation, and when the loss of the public good negatively affects all group members, then free-riding becomes a costly strategy (Archetti 2009; Diekmann 1985).

These findings have implications for the potential proximate functions of increased in-group cohesion in relation to out-group threat. Similar to other types of competitive interactions, intergroup conflict may lead to increased anxiety and the potential disturbance of intragroup relationships (Radford et al. 2016). For instance, chimpanzee intergroup encounters are associated with increased hypothalamic-pituitary-adrenal axis activity in both males and females (Samuni et al. 2019; Sobolewski 2012; Wittig et al. 2016). Therefore, one potential function of increased in-group cohesion in the aftermath of intergroup competition is to reduce anxiety and stress (Radford et al. 2016). Furthermore, as intragroup cooperation and strength in numbers are key components of successful intergroup interactions, increased intragroup cohesion may facilitate joint participation and prevent defection during conflicts with out-groups, which may avert power imbalance in favor of rivals.

Association in relatively large parties is a mechanism through which individuals may increase the predictability of coalitionary support, an essential element in both anxiety reduction and the reinforcement of cooperative participation (Radford et al. 
2016). Furthermore, the two social groups also showed a decrease in subgroup division (modularity) that is associated with territorial activity participation. Together these results highlight that group members not only associated in larger parties, but also associated with many individuals across the group, rather than focusing on a few partners or associating randomly with no clear preference. In addition, we showed that previous engagement in territorial activity (group defense score) led to increased party size in males and females, demonstrating a long-term effect of out-group interactions on chimpanzee association patterns. This showed that association patterns remained more cohesive days after the territorial activity ended, even when anxiety should potentially be dampened. Taken together, variation in modularity and immediate and long-term association patterns more strongly support the hypothesis that in-group cohesion may facilitate current and future intergroup competition participation rather than reduce anxiety.

Furthermore, we found that males, but not females, were less aggressive toward adult in-group members on days that they participated in territorial activity, but that there was no long-term post effect of the group defense score on intragroup aggression, likely because of the importance of male-male competition over mating opportunities in chimpanzees. Increased intragroup aggression in association with territorial activity is suggested to function as a herding behavior (Cooper et al. 2004) or punishment of free-riders (Arseneau-Robar et al. 2016), or to occur as a result of increased anxiety (Radford et al. 2016). However, increased intragroup aggression is likely to disturb ingroup relationships (Aureli 1997; Wittig and Boesch 2005) and cohesion (Cords 1992), thus potentially reducing the predictability of coalitionary support during intergroup competition or the ability to cooperate as a group. Following this, our findings of reduced intragroup aggression in males on days of territorial activity can be seen as a mechanism of conflict management, supporting the prediction that more cohesive (less aggressive) in-group dynamics promote collective action during conflicts with outgroups.

Contrary to observations of other chimpanzee populations, rates of intergroup lethal violence, including infanticide, are low in the Taï population (Wilson et al. 2014), and females participate in the vast majority of intergroup encounters and border patrols (Samuni et al., 2017). Regular female participation in territorial activity in Taï provides a rare opportunity to investigate the potential effects of intergroup competition on ingroup dynamics simultaneously in both sexes. The observed sex differences in the effect of territorial activity on intragroup aggression are likely a result of the higher aggressive nature of males and the different roles the sexes take during territorial activity. For instance, as numerical assessment of male but not female participants is suggested to determine the relative dominance of a specific group (Furuichi in press; Wilson et al. 2014), and because territorial activity is driven mainly by males, it is in the interest of males, more than females, to reinforce solidarity. As such, it is not surprising that we found an attenuation effect of territorial activity on intragroup aggression in males but not females. However, both sexes are expected to benefit from successful intergroup interactions (Mitani et al. 2010), and power imbalance in favor of the group promotes potential access to benefits (e.g., food resources and mating opportunities) for both sexes (Wrangham 1999). Therefore, in a population such as Taï with minimal rates of lethal intergroup violence, and high gregariousness of both sexes (Lehmann and 
Boesch 2009), the link between territorial activity and larger association parties is expected in both males and females.

Overall group size may influence group cohesion and the likelihood to participate in territorial activities. For example, the degree of chimpanzee group cohesion may increase with an overall reduction in group size (Lehmann and Boesch 2004), and chimpanzee males are less likely to participate in border patrols with an increase in male group size (Langergraber et al. 2017). According to predictions of the volunteer's dilemma, a minimum number of cooperating individuals should be required to secure the public good (Archetti 2009; Diekmann 1985). Thus, small sizes of groups may promote not only group cohesion, but also joint territorial activity participation of group members, both male and female, to ensure the public good. In this vein, it is possible that regular mixed-sex participation in territorial activities in Taï is a result of the relatively small adult group size of the two study groups (5 males, 10-16 females). Comparing the factors that influence female participation in territorial activity and the effects of territorial activity on female in-group dynamics across chimpanzee populations with varying sizes of social groups would be an important next step in examining the evolutionary origins of sex-specific tendencies for out-group hostility.

Our results, demonstrating that intergroup competition precipitates positive in-group dynamics, accord with previous findings in human (Bernhard et al. 2006; Gneezy and Fessler 2012; Puurtinen and Mappes 2009; Yamagishi and Mifune 2009), and nonhuman animals (Bruintjes et al. 2015; Majolo et al. 2016; Mirville et al. in press; Radford 2008; Samuni et al. 2017). Conversely, there is substantial lack of evidence for the effect of intergroup competition on positive in-group dynamics across primate species (Cheney 1992; Chism and Rogers 2004; Grueter 2013; Polizzi di Sorrentino et al. 2012; Yi et al. 2019). Evident variability in how intergroup competition and in-group cohesion are linked across studies and species provides an important basis to ask what potential selective pressures explain interstudy or interspecies discrepancies. For example, as variation in the balance between the costs and benefits of certain acts are theorized to drive selection, the link between intergroup conflict and in-group dynamics might be more pronounced in species in which immediate costs (e.g., severe injury) of intergroup competition are high, and countering such costs has clear fitness consequences. One would subsequently predict that in comparison to chimpanzees, this pattern will be less evident in species with more tolerant intergroup relations, such as bonobos (Furuichi in press; Moscovice et al. in press). Therefore, future studies on intergroup conflict and in-group dynamics would benefit from a comparative approach to elucidate the potential costs of intergroup interactions in the group and/or species.

Taken together, collective action and in-group cohesion during intergroup competition in chimpanzee likely act to facilitate future participation in intergroup competition, overcoming the collective action problem. Our results fit with the volunteer's dilemma (Archetti 2009; Diekmann 1985), which posits that free-riding should be costly if all group members suffer from the loss of the public good. The proximate mechanisms by which chimpanzee collective action during intergroup competition may be maintained likely involve an increase in the size of parties and reduced intragroup aggression. Furthermore, consistent participation of both sexes during intergroup competition in Taï is likely to avert large power imbalance between groups. Lethal attacks in chimpanzees occur mainly on isolated individuals (Wilson et al. 2014); thus minimizing power imbalances during encounters by mixed-sex participation reduces the probability of 
lethal intergroup violence. We cannot address whether consistent female participation is a result of or is a contributor to the low rates of lethal intergroup violence observed in this population. Nonetheless, our findings indicate that the link between out-group hostility and competition, and in-group solidarity and cohesion is shared between humans and chimpanzees.

Acknowledgements We thank the Ministère de l'Enseignement Supérieur et de la Recherche Scientifique and the Ministère de Eaux et Fôrests in Côte d'Ivoire, and the Office Ivoirien des Parcs et Réserves for permitting the study. We are grateful to the Centre Suisse de Recherches Scientifiques en Côte d'Ivoire and the staff members of the Taï Chimpanzee Project for their support. Core funding for the Taï Chimpanzee Project is provided by the Max Planck Society since 1997. This study was also funded by the Minerva Foundation, Leakey Foundation, and the European Research Council (ERC) under the European Union's Horizon 2020 research and innovation programme (Grant Agreement No 679787). We thank the editors and anonymous reviewers for their helpful input.

Author Contributions LS carried out the field data collection and data analysis, designed the study, and drafted the manuscript. AM carried out the field data collection and implementation of the elo-rank and revised the manuscript. AP carried out the field data collection and revised the manuscript. CC and RMW participated in the design of the study and manuscript revision. All authors gave final approval for publication.

Funding Information Open access funding provided by Max Planck Society.

Open Access This article is distributed under the terms of the Creative Commons Attribution 4.0 International License (http://creativecommons.org/licenses/by/4.0/), which permits unrestricted use, distribution, and reproduction in any medium, provided you give appropriate credit to the original author(s) and the source, provide a link to the Creative Commons license, and indicate if changes were made.

\section{References}

Altmann, J. (1974). Observational study of behavior: Sampling methods. Behaviour, 49(3-4), 227-266.

Anderson, D. P., Nordheim, E. V., Boesch, C., \& Moermond, C. (2002). Factors influencing fission-fusion grouping in chimpanzees in the Taï National Park, Côte D'Ivoire. In C. Boesch, G. Hohmann, \& L. F. Marchant (Eds.), Behavioural diversity in chimpanzees and Bonobos (pp. 90-101). Cambridge: Cambridge University Press.

Anderson, D. P., Nordheim, E. V., Moermond, T. C., Gone Bi, Z. B., \& Boesch, C. (2005). Factors influencing tree phenology in Taï National Park, Côte d'Ivoire1. Biotropica, 37(4), 631-640.

Archetti, M. (2009). Cooperation as a volunteer's dilemma and the strategy of conflict in public goods games. Journal of Evolutionary Biology, 22(11), 2192-2200.

Arseneau-Robar, T. J. M., Taucher, A. L., Müller, E., van Schaik, C., Bshary, R., \& Willems, E. P. (2016). Female monkeys use both the carrot and the stick to promote male participation in intergroup fights. Proceedings of the Royal Society B: Biological Sciences, 283(1843), 20161817.

Aureli, F. (1997). Post-conflict anxiety in nonhuman primates: The mediating role of emotion in conflict resolution. Aggressive Behavior, 23(5), 315-328.

Aureli, F., Cords, M., \& van Schaik, C. P. (2002). Conflict resolution following aggression in gregarious animals: A predictive framework. Animal Behaviour, 64(3), 325-343.

Baayen, R. H. (2008). Analyzing linguistic data: A practical introduction to statistics using $R$, 1 st ed. Cambridge: New York: Cambridge University Press.

Barr, D. J., Levy, R., Scheepers, C., \& Tily, H. J. (2013). Random effects structure for confirmatory hypothesis testing: Keep it maximal. Journal of Memory and Language, 68(3), 255-278.

Bates, D., Maechler, M., Bolker, B., \& Walker, S. (2015). Fitting linear mixed-effects models using lme4. Journal of Statistical Software, 67(1), 1-48.

Bernhard, H., Fischbacher, U., \& Fehr, E. (2006). Parochial altruism in humans. Nature, 442(7105), 912-915. 
Boesch, C., \& Boesch-Achermann, H. (2000). The chimpanzees of the Taï Forest: Behavioural ecology and evolution. Oxford: Oxford University Press.

Boesch, C., Crockford, C., Herbinger, I., Wittig, R., Moebius, Y., \& Normand, E. (2008). Intergroup conflicts among chimpanzees in Taï National Park: Lethal violence and the female perspective. American Journal of Primatology, 70(6), 519-532.

Bowles, S. (2009). Did warfare among ancestral hunter-gatherers affect the evolution of human social behaviors? Science, 324(5932), 1293-1298.

Bruintjes, R., Lynton-Jenkins, J., Jones, J. W., \& Radford, A. N. (2015). Out-group threat promotes withingroup affiliation in a cooperative fish. The American Naturalist, 187(2), 274-282.

Carron, A. V., \& Brawley, L. R. (2000). Cohesion: Conceptual and measurement issues. Small Group Research, 31(1), 89-106.

Cheney, D. L. (1992). Intragroup cohesion and intergroup hostility: The relation between grooming distributions and intergroup competition among female primates. Behavioral Ecology, 3(4), 334-345.

Chism, J., \& Rogers, W. (2004). Grooming and social cohesion in patas monkeys and other guenons. In M. E. Glenn \& M. Cords (Eds.), The guenons: Diversity and adaptation in African monkeys. Developments in Primatology: Progress and Prospects (pp. 233-244). New York: Springer Science+Business Media.

Clauset, A., Newman, M. E. J., \& Moore, C. (2004). Finding community structure in very large networks. Physical Review E, 70(6), 066111.

Cooper, M. A., Aureli, F., \& Singh, M. (2004). Between-group encounters among bonnet macaques (Macaca radiata). Behavioral Ecology and Sociobiology, 56(3), 217-227.

Cords, M. (1992). Post-conflict reunions and reconciliation in long-tailed macaques. Animal Behaviour, 44(1), 57-61.

Crofoot, M. C., \& Wrangham, R. W. (2010). Intergroup aggression in primates and humans: The case for a unified theory. In P. M. Kappeler \& J. Silk (Eds.), Mind the gap: Tracing the origins of human universals (pp. 171-195). Berlin: Springer.

Csardi, G., \& Nepusz, T. (2006). The igraph software package for complex network research. InterJournal, Complex Systems, 1695. http://igraph.org.

de Waal, F. B. M. (2000). Primates: A natural heritage of conflict resolution. Science, 289(5479), 586-590.

Diekmann, A. (1985). Volunteer's dilemma. Journal of Conflict Resolution, 29(4), 605-610.

Farine, D. R., \& Whitehead, H. (2015). Constructing, conducting and interpreting animal social network analysis. Journal of Animal Ecology, 84(5), 1144-1163.

Field, A. (2013). Discovering statistics using IBM SPSS statistics. Los Angeles: SAGE.

Foerster, S., Franz, M., Murray, C. M., Gilby, I. C., \& Feldblum, J. T. (2016). Chimpanzee females queue but males compete for social status. Scientific Reports, 6, 35404.

Forstmeier, W., \& Schielzeth, H. (2011). Cryptic multiple hypotheses testing in linear models: Overestimated effect sizes and the winner's curse. Behavioral Ecology and Sociobiology, 65(1), 47-55.

Fox, J., \& Weisberg, S. (2011). An R companion to applied regression. Thousand Oaks, CA: SAGE.

Furuichi, T. (in press). Variations in the intergroup relationships between species, between local populations, and within local populations in African great apes. International Journal of Primatology.

Gneezy, A., \& Fessler, D. M. T. (2012). Conflict, sticks and carrots: War increases prosocial punishments and rewards. Proceedings of the Royal Society of London B: Biological Sciences, 279(1727), 219-223.

Grueter, C. C. (2013). No effect of inter-group conflict on within-group harmony in non-human primates. Communicative \& Integrative Biology, 6(6), e26801.

Kitchen, D. M., \& Beehner, J. C. (2007). Factors affecting individual participation in group-level aggression among non-human primates. Behaviour, 144(12), 1551-1581.

Langergraber, K. E., Watts, D. P., Vigilant, L., \& Mitani, J. C. (2017). Group augmentation, collective action, and territorial boundary patrols by male chimpanzees. Proceedings of the National Academy of Sciences of the USA, 114(28), 7337-7342.

Lehmann, J., \& Boesch, C. (2004). To fission or to fusion: Effects of community size on wild chimpanzee (Pan troglodytes verus) social organisation. Behavioral Ecology and Sociobiology, 56(3), 207-216.

Lehmann, J., \& Boesch, C. (2009). Sociality of the dispersing sex: The nature of social bonds in West African female chimpanzees, Pan troglodytes. Animal Behaviour, 77(2), 377-387.

Majolo, B., de Bortoli Vizioli, A., \& Lehmann, J. (2016). The effect of intergroup competition on intragroup affiliation in primates. Animal Behaviour, 114, 13-19.

Majolo, B., deBortoli Vizioli, A., Inigo, L. M., \& Lehmann, J. (2019). The effect of group size and individual characteristics on between-group encounters in primates. International Journal of Primatology. https://doi.org/10.1007/s10764-019-00119-5. (this issue) 
McCarthy, M. S., Després-Einspenner, M.-L., Samuni, L., Mundry, R., Lemoine, S., et al (2018). An assessment of the efficacy of camera traps for studying demographic composition and variation in chimpanzees (Pan troglodytes). American Journal of Primatology, 80(9), e22904.

Mielke, A., Samuni, L., Preis, A., Gogarten, J. F., Crockford, C., \& Wittig, R. M. (2017). Bystanders intervene to impede grooming in Western chimpanzees and sooty mangabeys. Royal Society Open Science, 4(11), 171296.

Mirville, O. M., Ridley, A. M., Samedi, J. P. M., Vecellio, V., \& Ndagijimana, F. (in press). Intragroup behavioural changes following intergroup conflict in mountain gorillas (Gorilla beringei beringei). International Journal of Primatology.

Mitani, J. C., Watts, D. P., \& Amsler, S. J. (2010). Lethal intergroup aggression leads to territorial expansion in wild chimpanzees. Current Biology, 20(12), R507-R508.

Moscovice, L. R., Fruth, B., Hohmann, G., Trumble, B. C., \& Jaeggi, A. V. (in press). Dominance or tolerance? Evaluating ecological, social, and hormonal correlates of a prolonged period of inter-group encounters among LuiKotale bonobos. International Journal of Primatology.

Neumann, C., Duboscq, J., Dubuc, C., Ginting, A., Irwan, A. M., et al (2011). Assessing dominance hierarchies: Validation and advantages of progressive evaluation with Elo-rating. Animal Behaviour, 82(4), 911-921.

Newman, M. E. J. (2006). Modularity and community structure in networks. Proceedings of the National Academy of Sciences of the USA, 103(23), 8577-8582.

Olson, M. (1965). The logic of collective action. Cambridge, MA: Harvard University Press.

Polizzi di Sorrentino, E., Schino, G., Massaro, L., Visalberghi, E., \& Aureli, F. (2012). Between-group hostility affects within-group interactions in tufted capuchin monkeys. Animal Behaviour, 83(2), 445-451.

Preis, A., Samuni, L., Deschner, T., Crockford, C., \& Wittig, R. M. (2009). Group specific social dynamics affect urinary oxytocin levels in Tai male chimpanzees. In C. Boesch \& R. M. Wittig (Eds.), The Tai chimpanzees: 40 years of research. Cambridge: Cambridge University Press.

Puurtinen, M., \& Mappes, T. (2009). Between-group competition and human cooperation. Proceedings of the Royal Society of London B: Biological Sciences, 276(1655), 355-360.

Quinn, G. P., \& Keough, M. J. (2002). Experimental design and data analysis for biologists. Cambridge: Cambridge University Press.

R Core Team (2016). R: A language and environment for statistical computing. Vienna, Austria: R Foundation for Statistical Computing https://www.R-project.org/.

Radford, A. N. (2008). Duration and outcome of intergroup conflict influences intragroup affiliative behaviour. Proceedings of the Royal Society of London B: Biological Sciences, 275(1653), 2787-2791.

Radford, A. N., \& Fawcett, T. W. (2014). Conflict between groups promotes later defense of a critical resource in a cooperatively breeding bird. Current Biology, 24(24), 2935-2939.

Radford, A. N., Majolo, B., \& Aureli, F. (2016). Within-group behavioural consequences of between-group conflict: A prospective review. Proceedings of the Royal Society of London B, 283(1843), 20161567.

Rusch, H., \& Gavrilets, S. (2017). The logic of animal intergroup conflict: A review. Journal of Economic Behavior \& Organization. https://doi.org/10.1016/j.jebo.2017.05.004.

Samuni, L., Preis, A., Deschner, T., Crockford, C., \& Wittig, R. M. (2018b). Reward of labor coordination and hunting success in wild chimpanzees. Communications Biology, 1(1), 138.

Samuni, L., Preis, A., Deschner, T., Wittig, R. M., \& Crockford, C. (2019). Cortisol and oxytocin show independent activity during chimpanzee intergroup conflict. Psychoneuroendocrinology, 104, 165-173.

Samuni, L., Preis, A., Mielke, A., Deschner, T., Wittig, R. M., \& Crockford, C. (2018a). Social bonds facilitate cooperative resource sharing in wild chimpanzees. Proceedings of the Royal Society of London B: Biological Sciences, 285(1888), 20181643.

Samuni, L., Preis, A., Mundry, R., Deschner, T., Crockford, C., \& Wittig, R. M. (2017). Oxytocin reactivity during intergroup conflict in wild chimpanzees. Proceedings of the National Academy of Sciences of the USA, 114(2), 268-273.

Schielzeth, H. (2010). Simple means to improve the interpretability of regression coefficients. Methods in Ecology and Evolution, 1(2), 103-113.

Schielzeth, H., \& Forstmeier, W. (2009). Conclusions beyond support: Overconfident estimates in mixed models. Behavioral Ecology, 20(2), 416-420.

Sobolewski, M. E. (2012). The hormonal correlates of male chimpanzee social behavior. PhD thesis, University of Michigan.

Stolwijk, A. M., Straatman, H., \& Zielhuis, G. A. (1999). Studying seasonality by using sine and cosine functions in regression analysis. Journal of Epidemiology \& Community Health, 53(4), 235-238.

Watts, D. P., \& Mitani, J. C. (2001). Boundary patrols and intergroup encounters in wild chimpanzees. Behaviour, 138(3), 299-327. 
Wessling, E. G., Deschner, T., Mundry, R., Pruetz, J. D., Wittig, R. M., \& Kühl, H. S. (2018). Seasonal variation in physiology challenges the notion of chimpanzees (Pan troglodytes verus) as a forest-adapted species. Frontiers in Ecology and Evolution, 6,60.

Willems, E. P., Arseneau-Robar, T. J. M., Xenia, S., \& van Schaik, C. P. (2015). Communal range defence in primates as a public goods dilemma. Philosophical Transactions of the Royal Society B: Biological Sciences, 370(1683), 20150003.

Willems, E. P., Hellriegel, B., \& van Schaik, C. P. (2013). The collective action problem in primate territory economics. Proceedings of the Royal Society of London B: Biological Sciences, 280(1759), 20130081.

Wilson, M. L. (2013). Chimpanzees, warfare, and the invention of peace. In D. P. Fry (Ed.), War, peace, and human nature (pp. 361-388). Oxford: Oxford University Press.

Wilson, M. L., Boesch, C., Fruth, B., Furuichi, T., Gilby, I. C., et al (2014). Lethal aggression in Pan is better explained by adaptive strategies than human impacts. Nature, 513(7518), 414-417.

Wittig, R. M., \& Boesch, C. (2005). How to repair relationships: Reconciliation in wild chimpanzees (Pan troglodytes). Ethology, 111(8), 736-763.

Wittig, R. M., Crockford, C., Weltring, A., Langergraber, K. E., Deschner, T., \& Zuberbühler, K. (2016). Social support reduces stress hormone levels in wild chimpanzees across stressful events and everyday affiliations. Nature Communications, 7, 13361.

Worton, B. J. (1989). Kernel methods for estimating the utilization distribution in home-range studies. Ecology, 70(1), 164-168.

Wrangham, R. W. (1999). Evolution of coalitionary killing. American Journal of Physical Anthropology (Suppl.), 29, 1-30.

Wrangham, R. W., \& Glowacki, L. (2012). Intergroup aggression in chimpanzees and war in nomadic huntergatherers. Human Nature, 23(1), 5-29.

Yamagishi, T., \& Mifune, N. (2009). Social exchange and solidarity: In-group love or out-group hate? Evolution and Human Behavior, 30(4), 229-237.

Yi, Y., Fichtel, C., Kim, E., \& Choe, J. C. (2019). Impacts of inter-group interactions on intra-group behavioral changes in Javan gibbons (Hylobates moloch). International Journal of Primatology. https://doi. org/10.1007/s10764-019-00116-8. (this issue)

\section{Affiliations}

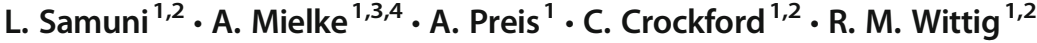

1 Department of Primatology, Max Planck Institute for Evolutionary Anthropology, Leipzig, Germany

2 Taï Chimpanzee Project, CSRS, Abidjan, Côte d'Ivoire

3 Department of Psychology, University of Portsmouth, Portsmouth, UK

4 Primate Models for Behavioural Evolution Lab, Institute for Cognitive and Evolutionary Anthropology, Oxford, UK 